\title{
Identification of Novel Protein Targets for Fenugreek to Treat Diabetes: A Molecular Docking Study
}

\author{
Haasini Nandyala ${ }^{1,2}$, Ariel Pham ${ }^{1,3}$, Anushka Wagle ${ }^{1,4}$, Hansika Daggolu', ${ }^{1,5}$, Amrita \\ Guha $^{1,6}$, Reya Sankar ${ }^{1,7}$, Chloe Chan ${ }^{1,8}$, Dipti Venkatesh ${ }^{1,9}$, Gayathri Renganathan ${ }^{1 \#}$ \\ 1'Department of Chemistry, Biochemistry, \& Physical Science, Aspiring Scholars Directed Research Pro- \\ gram (ASDRP) Fremont, CA, USA \\ BASIS Independent Silicon Valley, San Jose, CA, 95126. \\ ${ }^{3}$ Piedmont Hills High School, San Jose, CA, 95132. \\ ${ }^{4}$ Fremont High School, Sunnyvale, CA, 94087. \\ ${ }^{5}$ Mission San Jose High School, Fremont, CA, 94539. \\ ${ }^{6}$ Alsion Montessori Middle/High School, Fremont, CA, 94539. \\ ${ }^{7}$ Dougherty Valley High School, San Ramon, CA, 94582. \\ ${ }^{8}$ Lowell High School, San Francisco, CA, 94132. \\ ${ }^{9}$ Evergreen Valley High School, San Jose, CA, 95148. \\ \#Advisor
}

\section{$\underline{\text { ABSTRACT }}$}

Trigonella foenum-graecum has been shown to have anti-diabetic potential through a wide variety of in-vivo assays as well as by inhibiting enzymes such as alpha-glucosidase and alpha-amylase. Studies have indicated the therapeutic potential of different phytoconstituents found in Trigonella foenum-graceum including diosgenin trigonelline, 4-hydroxyisoleucine, leucine, and L-lysine. This study aims to find novel protein targets that these specific phytoconstituents from fenugreek can bind to, thereby helping to treat diabetes mellitus. Through multiple stages of molecular docking and analyzing the binding sites in comparison to previously reported inhibitors, a suitable and novel target protein for four of the compounds was found and the relevance to diabetes was discussed, setting up these compounds as novel inhibitors for the target proteins.

\section{Introduction}

Trigonella foenum-graecum, also known as fenugreek, is a short, annual plant from the Fabaceae family. It is found in various parts of the globe, and fenugreek leaves and seeds have been often used as a spice, condiment, and medication. In Africa, fenugreek is used as a supplement during bread preparation and the seed components of fenugreek are known to enhance the nutritional quality of the bread. In India, the leaves and seeds are utilized as flavoring and seasoning agents. In China, it is used to cure edema, and the ancient Egyptians employed fenugreek to incense the mummies ${ }^{1}$. Additionally, fenugreek has been recently studied for its therapeutic potential, including its antidiabetic ${ }^{2}$, antibacterial $^{3}$, antihyperlipidemic ${ }^{4}$, anti-angiogenic ${ }^{5}$, and anticoagulant factors ${ }^{6}$. Fenugreek seeds have been the most widely studied part of the plant and many potent active compounds have been identified. These major phytoconstituents include diosgenin, a sapogenin, which are lipophilic triterpene derivatives which protect plants against microbes, fungi, and other hostile organisms ${ }^{7}$; trigonelline, an alkaloid ${ }^{8,}$, which is a class of basic, naturally occurring organic compounds that contain at least one nitrogen atom; and 4-hydroxyisoleucine ${ }^{9}$, leucine, and lysine ${ }^{10}$, which are all amino acids. Amino acids are organic compounds that contain amino and carboxyl functional groups, along with a side chain specific to each amino acid, which are polymerized to form proteins. 
Diabetes mellitus is a chronic metabolic disease that is prevalent around the world; the IDF estimated that in 2019, the global estimate of adults with diabetes was 463 million $^{11}$. Diabetes mellitus is characterized by hyperglycemia, which is when there is too much sugar in the blood. This results in defective insulin secretion, resistance to insulin action, or both ${ }^{12}$. In type 1 diabetes mellitus, autoimmune destruction of pancreatic $\beta$-cells leads to a deficiency of insulin secretion, which results in metabolic derangements such as increased waist circumference, increased serum triglyceride levels, hypertension, and insulin resistance ${ }^{13}$. In addition, the function of pancreatic $\alpha$-cells is also abnormal, so there is excessive secretion of glucagons, which would normally be suppressed by hyperglycemia. On the other hand, in type 2 diabetes mellitus, individuals have detectable levels of insulin circulating in the body. However, they often are resistant to the action of insulin, due to impaired insulin secretion by the pancreas. This then causes increased glucose production in the liver, which leads to receptor and post-receptor defects, causing insulin resistance $^{14}$. Diabetes has been thoroughly studied, yet in spite of new medical devices and technology, it is projected that diabetes in the United States will increase by 54\% to more than 54.9 million Americans between 2015 and 2030 , annual deaths attributed to diabetes will climb by $38 \%$ to 385,800 , and total annual medical and societal costs related to diabetes will increase $53 \%$ to more than $\$ 622$ billion by $2030^{15}$.

With these projections, finding anti-diabetic therapeutics is crucial. Fenugreek has shown to have quite a lot of anti-diabetic potential. In terms of its hypoglycemic effect, many studies have tested fenugreek generally through animal and in vivo studies where animals were fed with either the seeds powders or extracts for a period of time from 5 days to several weeks or with a single dose treatment regimen ${ }^{16}$. The results generally showed that pretreatment with fenugreek resulted in lowered blood glucose and lipid levels in the mice or rats, indicating antidiabetic potential. Additionally, current research has focused on finding effective alpha-glucosidase and alpha-amylase inhibitors. Both of these enzymes are involved in the digestion of carbohydrates. Alpha-glucosidase is a membrane-bound enzyme present in the epithelium of the small intestine, which works to facilitate the absorption of glucose by the small intestine by catalyzing the hydrolytic cleavage of oligosaccharides into absorbable monosaccharides. $\alpha$-glucosidase inhibitors can retard the liberation of D-glucose from dietary complex carbohydrates and delay glucose absorption, resulting in reduced postprandial, or occurring after a meal, plasma glucose levels and suppression of postprandial hyperglycemia $^{17}$. Alpha-amylase enzymes, most importantly pancreatic alpha-amylase, act as catalysts in the reaction which involves the hydrolysis of the alpha-1,4 glycosidic linkages of the starch, amylopectin, amylose, glycogen, and numerous maltodextrins and is responsible for starch digestion. Similar to alpha-glucosidase, inhibiting alpha-amylase has been shown to decrease postprandial blood glucose levels ${ }^{18}$. In terms of fenugreek's ability to inhibit target proteins, diosgenin was shown to inhibit both alpha-glucosidase and alpha-amylase quite significantly through in-vitro studies $^{19}$.

Molecular docking is a method which predicts the preferred orientation of one molecule to a second when bound to each other to form a stable complex. Knowledge of the preferred pose is important to predict the strength of association or binding energy between two molecules. Characterization of the binding behavior to biomolecules plays an important role in rational design of drugs as well as to elucidate fundamental biochemical processes. For example, finding an inhibitor, which binds to that particular protein could prevent the action of some harmful proteins. Due to its ability to predict the binding-conformation of small molecule ligands to the appropriate target-binding site, molecular docking is one of the most frequently used methods in structure based drug design ${ }^{20}$. Traditionally, multiple ligands are screened against a certain protein target to find the ligand with the best binding energy score. However, when there is not much information about the molecular mechanism of the ligands, they undergo reverse docking, a process in which multiple protein targets are screened against a certain ligand and their docking complexes are reviewed.

\section{Methods}

\section{Reverse Docking}


Our group obtained SDF files of the five phytoconstituents from fenugreek: trigonelline ${ }^{21}$, diosgenin ${ }^{22}$, lysine ${ }^{23}$, leucine $^{24}$, and 4-hydroxyisoleucine ${ }^{25}$ were from PubChem. We then individually submitted these files to ACID, a novel web server that conducts inverse docking by using AutoDock Vina, LEDOCK, PLANTS, and PSOVina for binding pose search and docks the compounds against a i9 target database containing 831 protein structures from PDB ${ }^{26}$ covering 30 therapeutic areas ${ }^{27}$. After obtaining the reverse docking results for each compound, the top 30 target proteins (ranked in terms of binding energy) for each compound were selected and filtered first based on their enzyme class. The enzyme classes that our group selected were transferases, hydrolases, and oxidoreductases. The proteins from these classes were then screened for relevance to diabetes and the benefits of the protein being inhibited in relation to diabetes.

\section{Validation with AutoDock Vina}

In order to confirm the docking scores received from ACID, our group manually blind docked the target proteins that passed the screening against their respective compound using AutoDock Vina ${ }^{28}$. The docking score received from AutoDock Vina (ADV) was then compared with the score received from ACID.

\section{Analysis of Binding Sites}

Since blind docking was conducted, we used AutoDock Vina and Discovery Studio Visualizer ${ }^{29}$ (DS) to identify the amino acid residues for each protein-ligand complex and we also used Discovery Studio Visualizer to identify the specific interactions for each amino acid residue. In cases where an error occurred with AutoDock Vina, PyMol ${ }^{30}$ was used to determine the amino acid residues. In order to determine the amino acid residues through AutoDock Vina and PyMol, the output files created by manually docking and the target protein file were opened and analyzed by looking at the interactions. Similarly, the output file and protein file were opened on Discovery Studio Visualizer and the 2D interactions map was opened to identify the amino acid binding residues and the specific types of interactions. Additionally, in order to identify which proteins the ligands were actually inhibiting, we blind docked previously reported inhibitors for each target protein using AutoDock Vina and the amino acid residues from these dockings were compared to binding residues of the respective fenugreek compound. When comparing the phytoconstituents' docking to the inhibitors' docking, only conformations with the lowest RMSD values were studied.

\section{Results}

For each of the five compounds, there are three tables displaying the different results we obtained. The first table shows the top 30 target proteins based on binding energy we received from ACID. The second table depicts the ACID docking score, AutoDock Vina docking score, AutoDock Vina binding residues and the Discovery Studio binding residues for the screened and selected target proteins. The discrepancies between the ACID docking score and the AutoDock Vina score has been attributed to the fact that ACID used multiple docking softwares to come up with a docking score, and these other softwares are not accounted into the score received from AutoDock Vina. Additionally, the binding residues received from each software are very similar, but Discovery Studio was more specific in that for each amino acid residue, it also included what type of interaction was occurring between the residue and the ligand. Lastly the third table depicts the AutoDock Vina binding residues and docking score of the fenugreek compound and the reported inhibitor for each of the selected target proteins.

Table 1.1. Top 30 target proteins scored for diosgenin from ACID

\begin{tabular}{|l|l|l|l|}
\hline $\begin{array}{l}\text { Protein } \\
\text { Code }\end{array}$ & Protein Name & $\begin{array}{l}\text { Free Binding Energy } \\
(\mathrm{kcal} / \mathrm{mol})\end{array}$ & Docking Score $(\mathrm{kcal} / \mathrm{mol})$ \\
\hline
\end{tabular}




\begin{tabular}{|c|c|c|c|}
\hline 1NRL & Human PXR-LBD & -38.12 & -11.1 \\
\hline $5 \mathrm{HBS}$ & Human cellular retinol binding protein 1 & -37.74 & -10.95 \\
\hline $1 \mathrm{FCY}$ & $\begin{array}{l}\text { Human Retinoic Acid Nuclear Receptor } \\
\text { Hrar }\end{array}$ & -37.64 & -11.13 \\
\hline $1 \mathrm{SQN}$ & $\begin{array}{l}\text { Progesterone Receptor Ligand Binding } \\
\text { Domain }\end{array}$ & -37.07 & -11.6 \\
\hline $1 \mathrm{R} 20$ & Heterodimer EcR/USP & -36.82 & -11.21 \\
\hline 4UDD & Glucocorticoid Receptor & -36.66 & -11.5 \\
\hline $5 \mathrm{HJP}$ & LXRbeta Selective Agonists & -36.55 & -11.25 \\
\hline 4DM6 & RARb LBD homodimer & -35.98 & -11.05 \\
\hline $2 \mathrm{BZG}$ & Thiopurine S-methyltransferase & -35.94 & -11.04 \\
\hline $3 \mathrm{KMR}$ & RAR alpha ligand binding domain & -35.81 & -10.89 \\
\hline 1SQB & Bovine Bc1 & -35.66 & -10.22 \\
\hline $3 \mathrm{MY0}$ & ACVRL1 (ALK1) kinase & -35.27 & -10.35 \\
\hline 4QE6 & Human FXR & -35.26 & -11.27 \\
\hline $2 \mathrm{GL} 8$ & Retinoic acid receptor RXR-gamma & -34.78 & -9.07 \\
\hline $2 \mathrm{P} 1 \mathrm{~T}$ & Retinoid X receptor alpha & -34.71 & -11.48 \\
\hline 1CQX & Flavohemoglobin & -34.37 & -10.04 \\
\hline 3B0T & Human VDR ligand binding domain & -33.67 & -10.72 \\
\hline 2E2R & Human estrogen-related receptor gamma & -33.59 & -11.07 \\
\hline $4 \mathrm{~L} 8 \mathrm{U}$ & Human serum albumin & -33.18 & -10.41 \\
\hline $3 \mathrm{C} 6 \mathrm{~K}$ & Human spermine synthase & -33.1 & -9.55 \\
\hline 3BRT & NEMO/IKK & -33.09 & -10.21 \\
\hline $1 \mathrm{~W} 78$ & E.coli FolC & -32.44 & -9.42 \\
\hline 4QTB & Human ERK1 & -32.43 & -10.99 \\
\hline $2 \mathrm{HI} 4$ & Human Microsomal P450 1A2 & -32.41 & -10.71 \\
\hline 4BVM & Peripheral membrane protein $\mathrm{P} 2$ & -32.13 & -10.96 \\
\hline 4GQS & $\begin{array}{l}\text { Human Microsomal } \\
\text { P450: Cytochrome } \\
\text { (CYP) 2C19 }\end{array}$ & -31.78 & -10.19 \\
\hline 1D2S & $\begin{array}{l}\text { N-Terminal Laminin G-Like Domain } \\
\text { of:LE: }\end{array}$ & -31.57 & -10.19 \\
\hline $1 \mathrm{~T} 46$ & $\begin{array}{l}\text { Autoinhibition and STI-571 Inhibition } \\
\text { of fise-iC-KIT Tyrosine Kinase }\end{array}$ & -31.56 & -9.84 \\
\hline 2Q80 & $\begin{array}{l}\text { Human geranylgeranyl pyrophosphate } \\
\text { synthase bound to GGPP }\end{array}$ & -31.28 & -10 \\
\hline 4UYB & SEC14-like protein 3 & -31.28 & -11.15 \\
\hline
\end{tabular}

Table 2.1. Validation of docking of selected target proteins for diosgenin

\begin{tabular}{|l|l|l|l|l|l|l|}
\hline $\begin{array}{l}\text { PDB } \\
\text { Code }\end{array}$ & Name & Classification & $\begin{array}{l}\text { ACID } \\
\text { Docking }\end{array}$ & $\begin{array}{l}\text { AutoDock } \\
\text { Vina } \\
\text { Docking }\end{array}$ & $\begin{array}{l}\text { AutoDock Vina } \\
\text { Amino Acid Resi- } \\
\text { dues }\end{array}$ & $\begin{array}{l}\text { DS Amino Acid } \\
\text { Residues and Inter- } \\
\text { actions }\end{array}$ \\
\hline
\end{tabular}




\begin{tabular}{|l|l|l|l|l|l|l|}
\hline & & & $\begin{array}{l}\text { Score } \\
(\mathrm{kcal} / \mathrm{mol})\end{array}$ & $\begin{array}{l}\text { Score } \\
(\mathrm{kcal} / \mathrm{mol})\end{array}$ & & \\
\hline $\begin{array}{l}\text { 4QT } \\
\text { B }\end{array}$ & Human ERK1 & $\begin{array}{l}\text { Transferase/Trans- } \\
\text { ferase Inhibitor }\end{array}$ & -10.99 & -9.2 & $\begin{array}{l}\text { THR288, LYS289, } \\
\text { PHE313, THR312, } \\
\text { ASN314, LYS317 }\end{array}$ & $\begin{array}{l}\text { SER265: Carbon } \\
\text { hydrogen } \\
\text { LYS317: Alkyl } \\
\text { bond }\end{array}$ \\
\hline 2HI4 & $\begin{array}{l}\text { Human Microso- } \\
\text { mal P450 1A2 }\end{array}$ & Oxidoreductase & -10.71 & -8.2 & $\begin{array}{l}\text { GLN304, ASN309, } \\
\text { GLU305, VAL308, } \\
\text { PHE288, TYR272, } \\
\text { VAL268, GLN265 }\end{array}$ & VAL308: Pi Alkyl \\
TYR272: Alkyl
\end{tabular}

Table 3.1 Diosgenin vs. the reported inhibitors for each target protein

\begin{tabular}{|l|l|l|l|l|l|l|}
\hline $\begin{array}{l}\text { PDB } \\
\text { Code }\end{array}$ & Protein Name & $\begin{array}{l}\text { Diosgenin } \\
\text { ADV } \\
\text { Docking } \\
\text { Score } \\
(\mathrm{kcal} / \mathrm{mol})\end{array}$ & $\begin{array}{l}\text { Diosgenin ADV } \\
\text { Amino Acid Resi- } \\
\text { dues }\end{array}$ & $\begin{array}{l}\text { Reported In- } \\
\text { hibitor Name }\end{array}$ & $\begin{array}{l}\text { Reported } \\
\text { Inhibitor } \\
\text { ADV } \\
\text { Docking } \\
\text { Score } \\
(\mathrm{kcal} / \mathrm{mol})\end{array}$ & $\begin{array}{l}\text { Reported Inhibitor } \\
\text { ADV Amino Acid } \\
\text { Residues }\end{array}$ \\
\hline $\begin{array}{l}\text { 4QT } \\
\text { B }\end{array}$ & Human ERK1 & -9.2 & $\begin{array}{l}\text { THR288, LYS289, } \\
\text { PHE313, THR312, } \\
\text { ASN314, LYS317 }\end{array}$ & Ulixertinib & -9.7 & $\begin{array}{l}\text { TYR53, LYS71, } \\
\text { VAL56, ASP184, } \\
\text { GLU88, GLY186, } \\
\text { ARG84 }\end{array}$ \\
\hline 2HI4 & $\begin{array}{l}\text { Human Microso- } \\
\text { mal P450 1A2 }\end{array}$ & -8.2 & $\begin{array}{l}\text { GLN304, ASN309, } \\
\text { GLU305, VAL308, } \\
\text { PHE288, TYR272, } \\
\text { VAL268, GLN265 }\end{array}$ & Asenapine & -9.0 & $\begin{array}{l}\text { LEU382, THR385, } \\
\text { THR124, ALA317, } \\
\text { LEU497 }\end{array}$ \\
\hline
\end{tabular}

After comparing diosgenin's binding site to many reported inhibitors of each of the two target proteins 4QTB and 2HI4, human extracellular signal-regulated kinase (ERK1) and Cytochrome P450 1A2 (CYP1A2), our group found that diosgenin did not act as an inhibitor for either of the proteins. The reported inhibitor we used for ERK1 was ulixertinib31. For CYP1A2, we used asenapine32. For ERK1, diosgenin was compared to Figures 1 and 2, displaying the PyMol visualization of diosgenin's binding site and the reported inhibitors' binding sites for ERK1 and CYP1A2, respectively.

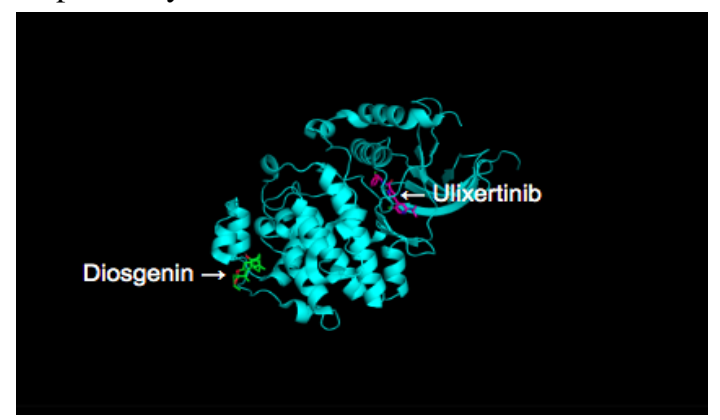

Fig 1

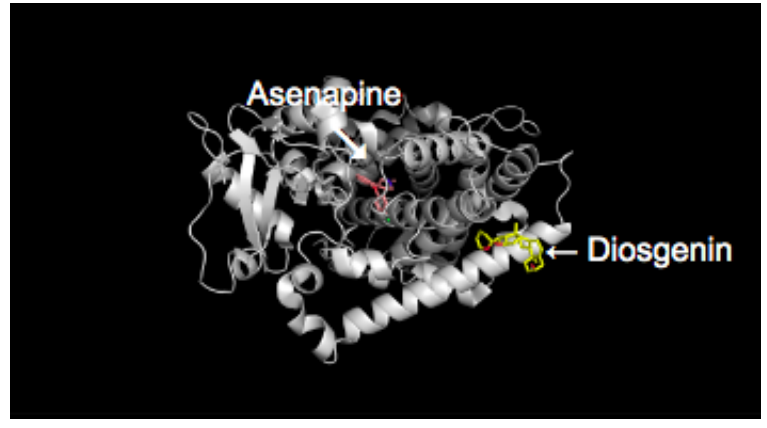

Fig 2 
Figure 1 Diosgenin and ulixertinib bound to human extracellular signal-regulated kinase (ERK1)

Figure 2 Diosgenin and asenapine bound to Cytochrome P450 1A2 (CYP1A2)

Table 1.2. Top 30 target proteins scored for trigonelline from ACID

\begin{tabular}{|c|c|c|c|}
\hline PDB Code & Protein Name & $\begin{array}{l}\text { Free Binding } \\
\text { Energy } \\
(\mathrm{kcal} / \mathrm{mol})\end{array}$ & $\begin{array}{l}\text { Docking score } \\
(\mathrm{kcal} / \mathrm{mol})\end{array}$ \\
\hline 3L6B & Human serine racemase & -55.07 & -6.56 \\
\hline $4 \mathrm{E} 1 \mathrm{O}$ & Human histidine decarboxylase & -53.4 & -6.68 \\
\hline $3 \mathrm{IIO}$ & Human Glutamate oxaloacetate transaminase 1 & -52.42 & -6.85 \\
\hline $3 \mathrm{KQJ}$ & MurA binary complex with UDP-N-acetylglucosamine & -45.79 & -6.4 \\
\hline $5 \mathrm{HHY}$ & Human Alanine:Glyoxylate Aminotransferase major allele & -45.22 & -6.86 \\
\hline $2 \mathrm{OOB}$ & Mycobacterium tuberculosis epsp synthase & -44.56 & -6.24 \\
\hline $3 \mathrm{C} 8 \mathrm{Y}$ & Fe-only hydrogenase & -43.35 & -6.59 \\
\hline 1D4D & $\begin{array}{l}\text { Flavocytochrome c fumarate reductase of shewanella putrefaciens } \\
\text { strain mr-1 }\end{array}$ & -42.7 & -6.42 \\
\hline 4USA & Aldehyde Oxidoreductase & -41.27 & -6.79 \\
\hline 2E1Q & Human Xanthine Oxidoreductase mutant & -40.83 & -6.64 \\
\hline $1 \mathrm{OTH}$ & $\begin{array}{l}\text { Human ornithine transcarbamoylase complexed with n-phosphona- } \\
\text { cetyl-1-ornithine }\end{array}$ & -39.46 & -6.82 \\
\hline 1FW1 & Glutathione transferase zeta/maleylacetoacetate isomerase & -38.78 & -6.75 \\
\hline $4 \mathrm{OQV}$ & Human dihydroorotate dehydrogenase bound with DSM338 & -38.49 & -6.87 \\
\hline 1SHA & $\begin{array}{l}\text { Phosphotyrosine recognition domain sh2 of v-src complexed with } \\
\text { tyrosine-phosphorylated peptides }\end{array}$ & -33.81 & -6.58 \\
\hline $2 \mathrm{~F} 71$ & Protein tyrosine phosphatase 1B with sulfamic acid inhibitors & -33.26 & -6.87 \\
\hline 2000 & Ornithine decarboxylase & -33.15 & -6.61 \\
\hline $5 \mathrm{KQL}$ & $\begin{array}{l}\text { LMW-PTP in complex with 2-oxo-1-phenyl-2-(phenyla- } \\
\text { mino)ethanesulfonic acid }\end{array}$ & -33 & -6.44 \\
\hline $4 Z Z 1$ & Human gar transformylase & -31.89 & -6.25 \\
\hline 2798 & AzoR (azoreductase) & -31.39 & -6.68 \\
\hline $2 \mathrm{GF3}$ & Monomeric sarcosine oxidase & -31.2 & -6.75 \\
\hline 3DDS & Glycogen phosphorylase & -30.06 & -6.53 \\
\hline $1 \mathrm{P5J}$ & Human Serine Dehydratase & -28.5 & -6.83 \\
\hline $3 \mathrm{~N} 9 \mathrm{Z}$ & Human CYP11A1 & -27.19 & -6.46 \\
\hline 1FDR & Flavodoxin reductase & -26.57 & -6.33 \\
\hline $1 \mathrm{PBE}$ & P-hydroxybenzoate hydroxylase & -26.37 & -6.87 \\
\hline $5 \mathrm{AX} 8$ & Human mitochondrial aspartate aminotransferase & -26.27 & -6.74 \\
\hline 2ZB4 & Human 15-ketoprostaglandin delta-13-reductase & -25.95 & -6.46 \\
\hline $1 \mathrm{Z6T}$ & Apoptotic protease-activating factor 1 & -25.86 & -6.58 \\
\hline $4 \mathrm{XNH}$ & Yeast N-terminal acetyltransferase NatE & -25.86 & -6.58 \\
\hline 1QO8 & Flavocytochrome c3 fumarate reductase & -25.18 & -6.43 \\
\hline
\end{tabular}


Table 2.2 Validation of docking of selected target proteins for trigonelline

\begin{tabular}{|c|c|c|c|c|c|c|}
\hline $\begin{array}{l}\text { PDB } \\
\text { Code }\end{array}$ & Protein Name & Classification & $\begin{array}{l}\text { ACID } \\
\text { Docking } \\
\text { Score } \\
(\mathrm{kcal} / \mathrm{mol})\end{array}$ & $\begin{array}{l}\text { Auto- } \\
\text { DockVina } \\
\text { Score } \\
(\mathrm{kcal} / \mathrm{mol})\end{array}$ & $\begin{array}{l}\text { AutoDockVina } \\
\text { Amino Acid Resi- } \\
\text { dues }\end{array}$ & $\begin{array}{l}\text { DS Amino Acid } \\
\text { Residues and Inter- } \\
\text { actions }\end{array}$ \\
\hline 2E1Q & $\begin{array}{l}\text { Xanthine Oxidore- } \\
\text { ductase }\end{array}$ & Oxidoreductase & -6.64 & -5.8 & $\begin{array}{l}\text { THR262, SER347, } \\
\text { GLY350* }\end{array}$ & $\begin{array}{l}\text { LEU257: Carbon } \\
\text { Hydrogen Bond } \\
\text { GLY350: Van der } \\
\text { Waals SER347: } \\
\text { Conventional Hy- } \\
\text { drogen Bond } \\
\text { GLU263: Conven- } \\
\text { tional Hydrogen } \\
\text { Bond } \\
\text { THR262: Conven- } \\
\text { tional Hydrogen } \\
\text { Bond } \\
\text { VAL259: Alkyl }\end{array}$ \\
\hline $2 \mathrm{~F} 71$ & $\begin{array}{l}\text { Protein tyrosine } \\
\text { phosphatase 1B }\end{array}$ & Hydrolase & -6.87 & -5.4 & $\begin{array}{l}\text { ARG199, ARG79, } \\
\text { LEU204 }\end{array}$ & $\begin{array}{l}\text { LEU204: Alkyl } \\
\text { ARG199: Conven- } \\
\text { tional Hydrogen } \\
\text { Bond, Salt Bridge } \\
\text { ARG79: Attractive } \\
\text { Charge }\end{array}$ \\
\hline $\begin{array}{l}5 \mathrm{KQ} \\
\mathrm{L}\end{array}$ & $\begin{array}{l}\text { Low molecular } \\
\text { weight Protein ty- } \\
\text { rosine phosphatase }\end{array}$ & $\begin{array}{l}\text { Hydrolase/hydro- } \\
\text { lase inhibitor }\end{array}$ & -6.44 & -5.5 & $\begin{array}{lr}\text { LEU13, } & \text { GLY14, } \\
\text { ARG18, } & \text { ILE16, } \\
\text { TYR131 } & \end{array}$ & $\begin{array}{l}\text { TYR131: Alkyl } \\
\text { ILE16: Pi-Alkyl } \\
\text { ARG18: } \\
\text { Bridge, Conven- } \\
\text { tional Hydrogen } \\
\text { Bond } \\
\text { LEU13: Conven- } \\
\text { tional Hydrogen } \\
\text { Bond GLY14: } \\
\text { Conventional Hyr- } \\
\text { dogen Bond } \\
\text { ASP129: Carbon } \\
\text { Hydrogen Bond }\end{array}$ \\
\hline $\begin{array}{l}\text { 3DD } \\
\mathrm{S}\end{array}$ & $\begin{array}{l}\text { Glycogen phos- } \\
\text { phorylase }\end{array}$ & Transferase & -6.53 & -4.9 & ASN631* & $\begin{array}{l}\text { ASN631: Conven- } \\
\text { tional Hydrogen } \\
\text { Bond ASP628: Un- } \\
\text { favorable Nega- } \\
\text { tive-Negative } \\
\text { ILE170: Alkyl }\end{array}$ \\
\hline
\end{tabular}

* PyMol was used to identify amino acid residues 
Table 3.2 Trigonelline vs. the reported inhibitors for each target protein

\begin{tabular}{|c|c|c|c|c|c|c|}
\hline $\begin{array}{l}\text { PDB } \\
\text { Code }\end{array}$ & Protein Name & $\begin{array}{l}\text { Trigonel- } \\
\text { line ADV } \\
\text { Docking } \\
\text { Score } \\
(\mathrm{kcal} / \mathrm{mol})\end{array}$ & $\begin{array}{l}\text { Trigonelline ADV } \\
\text { Amino Acid Resi- } \\
\text { dues }\end{array}$ & $\begin{array}{l}\text { Reported In- } \\
\text { hibitor Name }\end{array}$ & $\begin{array}{l}\text { Reported } \\
\text { Inhibitor } \\
\text { ADV } \\
\text { Docking } \\
\text { Score } \\
(\mathrm{kcal} / \mathrm{mol})\end{array}$ & $\begin{array}{l}\text { Reported Inhibitor } \\
\text { ADV Amino Acid } \\
\text { Residues }\end{array}$ \\
\hline $2 \mathrm{E} 1 \mathrm{Q}$ & $\begin{array}{l}\text { Xanthine Oxidore- } \\
\text { ductase }\end{array}$ & -5.8 & $\begin{array}{l}\text { THR262, SER347, } \\
\text { GLY350* }\end{array}$ & Allopurinol & -6.0 & $\begin{array}{l}\text { GLN1195, } \\
\text { ARG913, } \\
\text { SER1081, } \\
\text { ALA1080* }\end{array}$ \\
\hline $2 \mathrm{~F} 71$ & $\begin{array}{l}\text { Protein tyrosine } \\
\text { phosphatase } 1 \mathrm{~B}\end{array}$ & -5.4 & $\begin{array}{l}\text { ARG199, ARG79, } \\
\text { LEU204 }\end{array}$ & Ertiprotafib & -7.8 & $\begin{array}{l}\text { VAL49, } \\
\text { ALP48, } \\
\text { TYR417, ILE219, } \\
\text { TYE182 }\end{array}$ \\
\hline $\begin{array}{l}5 \mathrm{KQ} \\
\mathrm{L}\end{array}$ & $\begin{array}{l}\text { Low molecular } \\
\text { weight Protein ty- } \\
\text { rosine phosphatase }\end{array}$ & -5.5 & $\begin{array}{lr}\text { LEU13, } & \text { GLY14, } \\
\text { ARG18, } & \text { ILE16, } \\
\text { TYR131 } & \end{array}$ & $\begin{array}{l}\text { 2-(4-\{[3-(1- } \\
\text { Piperidi- } \\
\text { nyl)pro- } \\
\text { pyl]amino\}-2- } \\
\text { quino- } \\
\text { linyl)benzo- } \\
\text { nitrile }\end{array}$ & -7.8 & $\begin{array}{l}\text { ASP129, ARG18, } \\
\text { TYR131, GLY14, } \\
\text { GLU50, ILE16 }\end{array}$ \\
\hline $\begin{array}{l}\text { 3DD } \\
S\end{array}$ & $\begin{array}{l}\text { Glycogen phos- } \\
\text { phorylase }\end{array}$ & -4.9 & ASN631* & CP-316819 & -7.8 & $\begin{array}{l}\text { GLU123, GLU124, } \\
\text { LYS655* }\end{array}$ \\
\hline
\end{tabular}

* PyMol was used to identify amino acid residues

With trigonelline as the ligand, the target protein it inhibits is 5KQL, Low Molecular Weight Protein Tyrosine Phosphatase (LMWPTP). When trigonelline's binding site is compared to the reported inhibitor 2-(4- $\{[3-(1-P i p e r i d i-$ nyl)propyl]amino -2-quinolinyl)benzonitrile' $\mathrm{s}^{33}$ binding site, trigonelline binds to 5 out of the 6 same amino acid residues that the reported inhibitor binds to. These residues are ASP129, ARG18, TYR131, GLY14, and ILE16. Figure 3 and 4 shows the PyMol visualization of both ligands docked on to 5KQL, displaying how they have binded to the same site of the protein. Some of the interactions between the residues and trigonelline include alkyl, pi-alkyl, salt bridge, conventional hydrogen bonding and Carbon Hydrogen Bonding, showing a mix of strong polar bonds and noncovalent attractions that make it a stable complex.

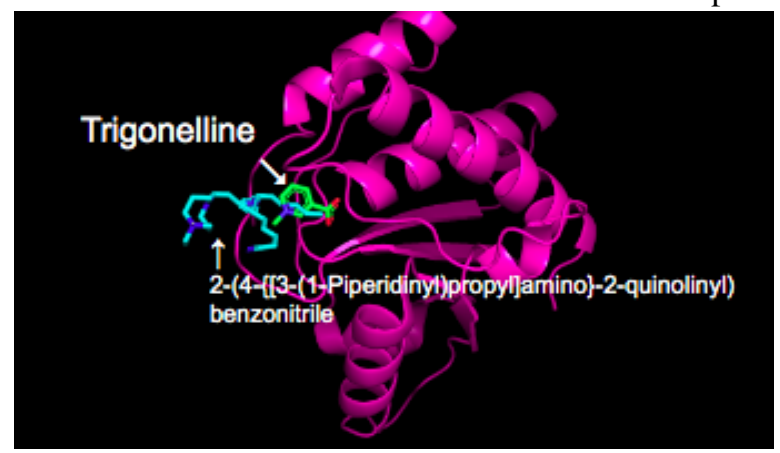

Fig 3

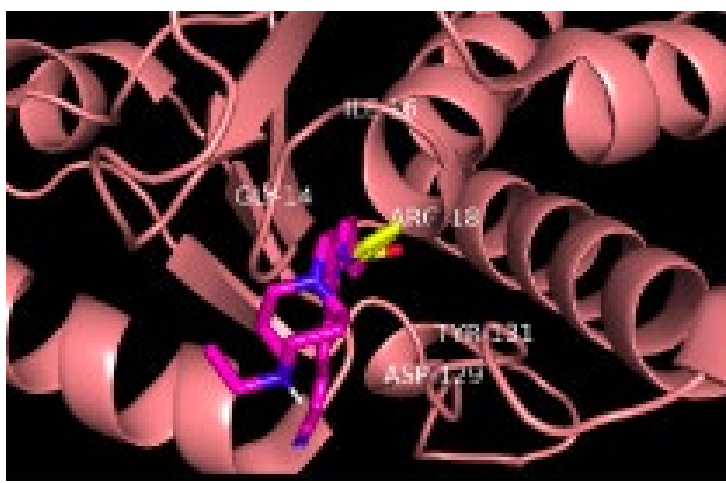

Fig 4 


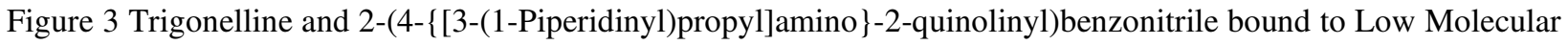
Weight Protein Tyrosine Phosphatase (LMWPTP)

Figure 4 Close-up view of binding complexes with Low Molecular Weight Protein Tyrosine Phosphatase (LMWPTP) with common binding residues labeled. The pink and blue ligand is 2-(4-\{[3-(1-Piperidinyl)propyl]amino\}-2-quinolinyl)benzonitrile and the yellow and red ligand is trigonelline.

Table 1.3 Top 30 target proteins scored for 4-hydroxyisoleucine from ACID

\begin{tabular}{|c|c|c|c|}
\hline PDB Code & Name & $\begin{array}{l}\text { Free Binding } \\
(\mathrm{kcal} / \mathrm{mol})\end{array}$ & Docking Score $(\mathrm{kcal} / \mathrm{mol})$ \\
\hline $5 \mathrm{CMM}$ & $\begin{array}{l}\text { GluK2EM LBD Dimer Assembly Com- } \\
\text { plex }\end{array}$ & -35.12 & -7.31 \\
\hline $4 \mathrm{MXU}$ & Aspartoacylase Mutant K213E Complex & -25.87 & -6.87 \\
\hline $3 \mathrm{~T} 3 \mathrm{M}$ & Integrin Alphallbbeta3 Receptor & -23.08 & -6.37 \\
\hline 3B6R & Human Brain-type Creatine Kinase & -22.51 & -6.33 \\
\hline $1 \mathrm{R} 76$ & Pectate Lyase from Azospirillum Irakense & -22.35 & -6.13 \\
\hline $2 \mathrm{WAD}$ & Penicillin-Binding Protein 2B (PBP-2B) & -21.75 & -6.6 \\
\hline $4 \mathrm{~V} 11$ & Synaptotagmin-1 with SV2A Peptide & -21.44 & -6.12 \\
\hline 4D1P & Nitric Oxide Synthases & -20.27 & -6.17 \\
\hline $1 \mathrm{U} 8 \mathrm{~V}$ & $\begin{array}{l}\text { 4-Hydroxybutyryl-CoA Dehydratase from } \\
\text { Clostridium Aminobutyricum }\end{array}$ & -20.23 & -6.52 \\
\hline 2OZL & Pyruvate Dehydrogenase & -20.03 & -6.8 \\
\hline $1 \mathrm{UNQ}$ & Protein Kinase B & -20 & -6 \\
\hline $3 \mathrm{IHJ}$ & Alanine Aminotransferase 2 & -19.58 & -6.57 \\
\hline 3B6R & Human Brain-type Creatine Kinase & -19.52 & -6.31 \\
\hline 5FQD & $\begin{array}{l}\text { Lenalidomide-Induced CK1a degradation } \\
\text { by the Cr14crbn Ubiquitin Ligase }\end{array}$ & -19.38 & -7.32 \\
\hline $2 \mathrm{Y} 2 \mathrm{M}$ & Penicillin-Binding Protein 1B & -19.33 & -6.52 \\
\hline 1CQX & $\begin{array}{l}\text { Flavohemoglobin from Alcaligenes Eu- } \\
\text { trophus }\end{array}$ & -19.2 & -6.14 \\
\hline $5 \mathrm{~K} 3 \mathrm{~S}$ & Acetohydroxyacid Synthase & -18.93 & -7.14 \\
\hline 1BUC & Butyryl-CoA Dehydrogenase & -18.85 & -6.84 \\
\hline 3P0C & Nischarin PX-Domain & -18.81 & -6.14 \\
\hline $2 \mathrm{~F} 25$ & Sialidase Neu2 E111Q & -18.71 & -6.5 \\
\hline $1 \mathrm{BUC}$ & Butyryl-CoA Dehydrogenase & -18.59 & -6.85 \\
\hline $4 \mathrm{XNH}$ & N-Terminal Acetyltransferase NatE & -18.5 & -6.5 \\
\hline $4 \mathrm{ZJB}$ & $\begin{array}{l}\text { C-terminal Domain of PyIRS Mutant } \\
\text { Bound with 3-Benzothienyl-1-alanine and } \\
\text { ATP }\end{array}$ & -18.34 & -6.5 \\
\hline $4 \mathrm{HBU}$ & $\begin{array}{l}\text { CTX-M-15 extended-spectrum Beta-Lac- } \\
\text { tamase }\end{array}$ & -18.17 & -6.53 \\
\hline $1 \mathrm{Y93}$ & Matrix Metalloproteinase 12 & -18.06 & -6.37 \\
\hline 3VE6 & $\begin{array}{l}\text { Venezuelan Equine Encephalitis Virus } \\
\text { Capsid Protein NLS and Importin Alpha }\end{array}$ & -17.95 & -6.17 \\
\hline
\end{tabular}




\begin{tabular}{|l|l|l|l|}
\hline 2V40 & $\begin{array}{l}\text { Human Adenylosuccinate Synthetase Iso- } \\
\text { zyme 2 in Complex with GDP }\end{array}$ & -17.74 & -6.31 \\
\hline 4MR7 & $\begin{array}{l}\text { Extracellular Domain of Human } \\
\text { GABA(B) receptor }\end{array}$ & -17.56 & -6.54 \\
\hline 2OUR & Phosphodiesterase 10 & -17.35 & -6.42 \\
\hline 3ZOO & Cytochrome C & -17.28 & -6.79 \\
\hline
\end{tabular}

Table 2.3 Validation of docking of selected target proteins for 4-hydroxyisoleucine

\begin{tabular}{|c|c|c|c|c|c|c|}
\hline $\begin{array}{l}\text { PDB } \\
\text { Code }\end{array}$ & Name & Classification & $\begin{array}{l}\text { ACID } \\
\text { Docking } \\
\text { Score } \\
(\mathrm{kcal} / \mathrm{mol})\end{array}$ & $\begin{array}{l}\text { AutoDock } \\
\text { Vina } \\
\text { Docking } \\
\text { Score } \\
(\mathrm{kcal} / \mathrm{mol})\end{array}$ & $\begin{array}{l}\text { AutoDock } \\
\text { Vina } \\
\text { Amino } \\
\text { Acid Resi- } \\
\text { dues }\end{array}$ & $\begin{array}{l}\text { DS Amino Acid Residues } \\
\text { and Interactions }\end{array}$ \\
\hline 3B6R & $\begin{array}{l}\text { Human Brain-type } \\
\text { Creatine Kinase }\end{array}$ & Transferase & -6.33 & -4.8 & $\begin{array}{l}\text { VAL75, } \\
\text { VAL72, } \\
\text { CYS283, } \\
\text { CYS74, } \\
\text { GLY73, } \\
\text { THR59, } \\
\text { LEU201, } \\
\text { LEU202 }\end{array}$ & $\begin{array}{l}\text { VAL72: Conventional Hy- } \\
\text { drogen Bond } \\
\text { THR71: Carbon Hydrogen } \\
\text { Bond } \\
\text { CYS74: Conventional Hy- } \\
\text { drogen Bond LEU201: } \\
\text { Conventional Hydrogen } \\
\text { Bond, Unfavorable Accep- } \\
\text { tor-Acceptor }\end{array}$ \\
\hline 4D1P & $\begin{array}{l}\text { Nitric Oxide Syn- } \\
\text { thases }\end{array}$ & Oxidoreductase & -6.17 & -5.9 & $\begin{array}{l}\text { THR80, } \\
\text { VAL465, } \\
\text { GLY440, } \\
\text { CYS441, } \\
\text { GLN435, } \\
\text { LEU431 }\end{array}$ & $\begin{array}{l}\text { GLN 435: Conventional } \\
\text { Hydrogen Bond LEU431: } \\
\text { Conventional Hydrogen } \\
\text { Bond } \\
\text { GLN 462: Conventional } \\
\text { Hydrogen Bond ASP82: } \\
\text { Conventional Hydrogen } \\
\text { Bond CYS441: Carbon Hy- } \\
\text { drogen Bond }\end{array}$ \\
\hline $3 \mathrm{IHJ}$ & $\begin{array}{l}\text { Alanine Ami- } \\
\text { notransferase } 2\end{array}$ & Transferase & -6.57 & -4.4 & $\begin{array}{l}\text { GLU421, } \\
\text { ALA417, } \\
\text { LEU435 }\end{array}$ & $\begin{array}{l}\text { LEU435: Conventional Hy- } \\
\text { drogen Bond (2) } \\
\text { GLU421: Salt Bridge, Con- } \\
\text { ventional Hydrogen Bond } \\
\text { PRO434: Alkyl }\end{array}$ \\
\hline 1YP3 & $\begin{array}{l}\text { Matrix Metallopro- } \\
\text { teinase } 12\end{array}$ & Hydrolase & -6.37 & -6 & $\begin{array}{l}\text { THR239, } \\
\text { TYR240, } \\
\text { LYS241, } \\
\text { LEU214, } \\
\text { VAL235, } \\
\text { PHE237 }\end{array}$ & $\begin{array}{l}\text { THR215: Carbon Hydrogen } \\
\text { Bond THR239: Conven- } \\
\text { tional Hydrogen Bond } \\
\text { HIS219: Attractive Charge, } \\
\text { Unfavorable Donor-Donor } \\
\text { VAL235: Conventional } \\
\text { Hydrogen Bond (2) }\end{array}$ \\
\hline
\end{tabular}




\begin{tabular}{|l|l|l|l|l|l|}
\hline & & & & & $\begin{array}{l}\text { PHE237: Conventional Hy- } \\
\text { drogen Bond LYS201: Un- } \\
\text { favorable Acceptor-Accep- } \\
\text { tor }\end{array}$ \\
\hline
\end{tabular}

Table 3.3 4-hydroxyisoleucine vs. the reported inhibitors for each target protein

\begin{tabular}{|c|c|c|c|c|c|c|}
\hline $\begin{array}{l}\text { PDB } \\
\text { Code }\end{array}$ & Protein Name & $\begin{array}{l}\text { 4-Hydrox- } \\
\text { yisoleu- } \\
\text { cine ADV } \\
\text { Docking } \\
\text { Score } \\
(\mathrm{kcal} / \mathrm{mol})\end{array}$ & $\begin{array}{l}\text { 4-Hydroxyisoleu- } \\
\text { cine ADV Amino } \\
\text { Acid Residues }\end{array}$ & $\begin{array}{l}\text { Reported In- } \\
\text { hibitor Name }\end{array}$ & $\begin{array}{l}\text { Reported } \\
\text { Inhibitor } \\
\text { ADV } \\
\text { Docking } \\
\text { Score } \\
(\mathrm{kcal} / \mathrm{mol}) \\
\end{array}$ & $\begin{array}{l}\text { Reported Inhibitor } \\
\text { ADV Amino Acid } \\
\text { Residues }\end{array}$ \\
\hline 3B6R & $\begin{array}{l}\text { Human Brain-type } \\
\text { Creatine Kinase }\end{array}$ & -4.8 & $\begin{array}{l}\text { VAL75, } \\
\text { VAL72, } \\
\text { CYS283, } \\
\text { CYS74, } \\
\text { GLY73, } \\
\text { THR59, } \\
\text { LEU201, } \\
\text { LEU202 }\end{array}$ & BU99006 & -5.8 & $\begin{array}{l}\text { THR71, MET70, } \\
\text { CYS283, VAL72, } \\
\text { LEU201, LEU202, } \\
\text { THR59, VAL75 }\end{array}$ \\
\hline 4D1P & $\begin{array}{l}\text { Nitric Oxide Syn- } \\
\text { thases }\end{array}$ & -5.9 & $\begin{array}{l}\text { THR80, } \\
\text { VAL465, } \\
\text { GLY440, } \\
\text { CYS441, } \\
\text { GLN435, } \\
\text { LEU431 }\end{array}$ & $\begin{array}{l}\text { L-N- } \\
\text { Methylarg- } \\
\text { inine (L- } \\
\text { NMA) }\end{array}$ & -6.3 & $\begin{array}{lr}\text { LYS72, } & \text { SER78, } \\
\text { ASN73, } & \text { GLN462, } \\
\text { THR80, } & \text { VAL465, } \\
\text { ASP82, } & \text { GLN435, } \\
\text { LEU431 } & \end{array}$ \\
\hline $3 \mathrm{IHJ}$ & $\begin{array}{l}\text { Alanine Ami- } \\
\text { notransferase } 2\end{array}$ & -4.4 & $\begin{array}{l}\text { GLU421, } \\
\text { ALA417, } \\
\text { LEU435 }\end{array}$ & L-cycloserine & -3.9 & $\begin{array}{l}\text { PRO309, LEU435, } \\
\text { LYS418, GLU421 }\end{array}$ \\
\hline 1YP3 & $\begin{array}{l}\text { Matrix Metallopro- } \\
\text { teinase } 12\end{array}$ & -6 & $\begin{array}{l}\text { THR239, } \\
\text { TYR240, } \\
\text { LYS241, } \\
\text { LEU214, } \\
\text { VAL235, } \\
\text { PHE237 }\end{array}$ & RXP470.1 & -4.8 & VAL235, LEU214 \\
\hline
\end{tabular}

With 4-hydroxyisoleucine as the ligand, all the target proteins were inhibited in some capacity but based on docking scores, interactions, and the number of common residues between trigonelline and the reported inhibitor, the most suitable protein for 4-hydroxyisoleucine is 4D1P, Nitric Oxide Synthase. Comparing 4-hydroxyisoleucine's binding to 4D1P with the reported inhibitor L-N-Methylarginine ${ }^{34}$ showed that 4-hydroxyisoleucine binds to 6 out of the 9 same amino acid residues as L-N-Methylarginine, with those being GLN462, THR80, VAL465, ASP82, GLN435, and LEU431. Figure 5 and 6 shows the PyMol visualization of both ligands docked on to 4D1P, displaying how they have binded to the same site of the protein. Interactions in this complex include many conventional hydrogen bonds and a Carbon Hydrogen bond and there are no unfavorable forces. These are very strong polar forces, making the attraction between the ligand and protein very stable. 


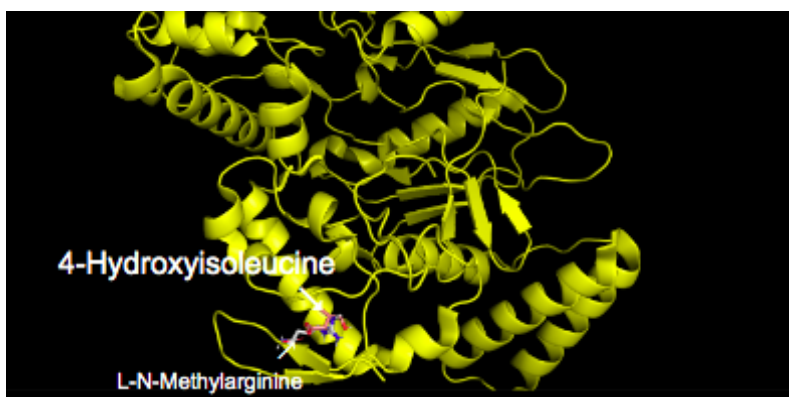

Fig 5

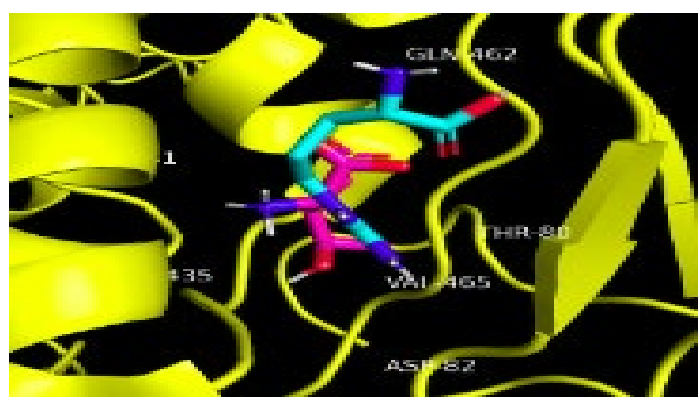

Fig 6

Figure 5 4-hydroxyisoleucine and L-N-Methylarginine bound to 4D1P

Figure 6 Close-up view of binding complexes with 4D1P with common binding residues labeled. The blue ligand is L-N Methylarginine and the pink ligand is 4-hydroxyisoleucine.

Table 1.4 Top 30 target proteins scored for leucine from ACID

\begin{tabular}{|l|l|l|l|}
\hline PDB Code & Name & $\begin{array}{l}\text { Free Binding Energy } \\
(\mathrm{kcal} / \mathrm{mol})\end{array}$ & Docking Score (kcal/mol) \\
\hline 5CMM & GluK2EM LBD dimer & -32.07 & -7.13 \\
\hline 3FV2 & Human glutamate receptor: GluR5 & -28.85 & -7.11 \\
\hline 1ITU & Human renal dipeptidase & -28.66 & -6.51 \\
\hline 5D6E & Human methionine aminopeptidase 2 & -27.54 & -6.6 \\
\hline 4V11 & Synaptotagmin-1 & -26.86 & -6.05 \\
\hline 2C46 & Human RNA guanylyltransferase & -25.28 & -6.42 \\
\hline 3BWY & $\begin{array}{l}\text { Human 108M catechol O-methyltransfer- } \\
\text { ase }\end{array}$ & -24.91 & -7.01 \\
\hline 3DYD & Human tyrosine aminotransferase & -24.67 & -6.6 \\
\hline 1U8V & $\begin{array}{l}\text { 4-Hydroxybutyryl-CoA dehydratase from } \\
\text { clostridium aminobutyricum }\end{array}$ & -24.54 & -6.55 \\
\hline 2NZ2 & Human argininosuccinate synthase & -24.3 & -6.64 \\
\hline 3T3M & Alphallbbeta3 receptor antagonist & -24.13 & -6.35 \\
\hline 4U3T & $\begin{array}{l}\text { Neisseria gonorrhoeae penicillin-binding } \\
\text { protein 2 derived from penicillin-resistant } \\
\text { strain 6140 }\end{array}$ & -23.72 & -6.27 \\
\hline 2BM0 & $\begin{array}{l}\text { Ribosomal elongation factor G (EF-G) } \\
\text { Fusidic acid resistant mutant T84A }\end{array}$ & -23.58 & -6.35 \\
\hline 1KNR & L-aspartate oxidase: R386 mutant & -22.56 & -6.74 \\
\hline 2CVD & $\begin{array}{l}\text { Human hematopoietic prostaglandin D } \\
\text { synthase }\end{array}$ & -21.81 & -6.28 \\
\hline 1GYX & $\begin{array}{l}\text { YdcE, a 4-Oxalocrotonate Tautomerase } \\
\text { Homologue from Escherichia coli }\end{array}$ & -21.48 & -6.49 \\
\hline 1CQX & $\begin{array}{l}\text { Flavohemoglobin from Alcaligenes eu- } \\
\text { trophus }\end{array}$ & -20.85 & -33 \\
\hline
\end{tabular}




\begin{tabular}{|l|l|l|l|}
\hline 3I4A & $\begin{array}{l}\text { Dimethylarginine dimethylaminohydro- } \\
\text { lase-1 (DDAH-1) }\end{array}$ & -20.84 & -6.73 \\
\hline 5K3S & $\begin{array}{l}\text { Arabidopsis thaliana acetohydroxyacid } \\
\text { synthase }\end{array}$ & -20.44 & -6.89 \\
\hline 3QFS & NADPH-Cytochrome P450 Reductase & -19.89 & -6.29 \\
\hline 3B6R & Human Brain-type Creatine Kinase & -19.87 & -6.35 \\
\hline 1UNQ & $\begin{array}{l}\text { Pleckstrin Homology Domain Of Protein } \\
\text { Kinase B/Akt }\end{array}$ & -19.85 & -5.98 \\
\hline 1FDR & Flavodoxin reductase from E. Coli & -19.19 & -6.5 \\
\hline 4RQR & Human Glutaredoxin & -19.15 & -6.07 \\
\hline 2OUR & PDE10A2 mutant D674A & -19.14 & -6.33 \\
\hline 3ODU & CXCR4 chemokine receptor & -19.14 & -6.43 \\
\hline 5F0X & $\begin{array}{l}\text { Human GRP78 (70kDa heat shock protein } \\
5 / \text { BIP) ATPase domain }\end{array}$ & -18.77 & -6.71 \\
\hline 1NP7 & $\begin{array}{l}\text { Synechocystis sp. PCC6803 crypto- } \\
\text { chrome }\end{array}$ & -18.55 & -6.5 \\
\hline 1COY & Cholesterol oxidase & -18.45 & -6.56 \\
\hline 5TC4 & $\begin{array}{l}\text { Human mitochondrial methylenetetrahy- } \\
\text { drofolate dehydrogenase-cyclohydrolase } \\
\text { (MTHFD2) }\end{array}$ & -18.39 & -6.52 \\
\hline
\end{tabular}

Table 2.4 Validation of docking of selected target proteins for leucine

\begin{tabular}{|l|l|l|l|l|l|l|}
\hline $\begin{array}{l}\text { PDB } \\
\text { Code }\end{array}$ & Name & Classification & $\begin{array}{l}\text { ACID } \\
\text { Docking } \\
\text { Score } \\
(\mathrm{kcal} / \mathrm{mol})\end{array}$ & $\begin{array}{l}\text { AutoDock } \\
\text { Vina } \\
\text { Docking } \\
\text { Score } \\
(\mathrm{kcal} / \mathrm{mol})\end{array}$ & $\begin{array}{l}\text { AutoDock Vina } \\
\text { Amino Acid Resi- } \\
\text { dues }\end{array}$ & $\begin{array}{l}\text { DS Amino Acid } \\
\text { Residues and Inter- } \\
\text { actions }\end{array}$ \\
\hline 3QFS & $\begin{array}{l}\text { NADPH- Cyo- } \\
\text { chrome P450 Re- } \\
\text { ductase }\end{array}$ & Oxidoreductase & -6.29 & -4.8 & $\begin{array}{l}\text { SER599, TYR607, } \\
\text { PRO536, VAL608 }\end{array}$ & $\begin{array}{l}\text { HIS231: Pi-Alkyl, } \\
\text { Salt Bridge, Posi- } \\
\text { tive-Positive } \\
\text { ILE338: Alkyl } \\
\text { HIS331: } \\
\text { Bridge Salt } \\
\text { PHE219: Pi-Sigma } \\
\text { ASP262: } \\
\text { Bridge (2) ASP251: } \\
\text { Salt } \\
\text { Bridge } \\
\text { Salt } \\
\text { GLU364: } \\
\text { Sridge GLU459: } \\
\text { Salt Bridge (3) }\end{array}$ \\
\hline
\end{tabular}




\begin{tabular}{|c|c|c|c|c|c|c|}
\hline $5 \mathrm{D} 6 \mathrm{E}$ & $\begin{array}{l}\text { Human methionine } \\
\text { aminopeptidase } 2\end{array}$ & Hydrolase & -6.6 & -5.7 & $\begin{array}{l}\text { ASP262, GLU364, } \\
\text { ILE338, ASP251, } \\
\text { PHE219, HIS231 }\end{array}$ & $\begin{array}{l}\text { TYR607: Pi-Sigma } \\
\text { SER599: Conven- } \\
\text { tional Hydrogen } \\
\text { Bond } \\
\text { MET638: Alkyl } \\
\text { PRO536: Alkyl } \\
\text { VAL608: Alkyl }\end{array}$ \\
\hline
\end{tabular}

Table 3.4 Leucine vs. the reported inhibitors for each target protein

\begin{tabular}{|l|l|l|l|l|l|l|}
\hline $\begin{array}{l}\text { PDB } \\
\text { Code }\end{array}$ & Protein Name & $\begin{array}{l}\text { Leucine } \\
\text { ADV } \\
\text { Docking } \\
\text { Score } \\
\mathrm{kcal} / \mathrm{mol})\end{array}$ & $\begin{array}{l}\text { Leucine ADV } \\
\text { Amino Acid Resi- } \\
\text { dues }\end{array}$ & $\begin{array}{l}\text { Reported In- } \\
\text { hibitor Name }\end{array}$ & $\begin{array}{l}\text { Reported } \\
\text { Inhibitor } \\
\text { ADV } \\
\text { Docking } \\
\text { Score } \\
(\mathrm{kcal} / \mathrm{mol})\end{array}$ & $\begin{array}{l}\text { Reported Inhibitor } \\
\text { ADV Amino Acid } \\
\text { Residues }\end{array}$ \\
\hline 3QFS & $\begin{array}{l}\text { NADPH- Cyo- } \\
\text { chrome P450 Re- } \\
\text { ductase }\end{array}$ & -4.8 & $\begin{array}{l}\text { SER599, TYR607, } \\
\text { PRO536, VAL608 }\end{array}$ & Fumagillin & -7.2 & $\begin{array}{l}\text { ASP262, PHE219, } \\
\text { HIS231, LEU328, } \\
\text { ASN329, HIS331, } \\
\text { HIS339, TYR444, } \\
\text { PRO443 }\end{array}$ \\
\hline 5D6E & $\begin{array}{l}\text { Human methionine } \\
\text { aminopeptidase 2 }\end{array}$ & -5.7 & $\begin{array}{l}\text { ASP262, GLU364, } \\
\text { ILE338, ASP251, } \\
\text { PHE219, HIS231 }\end{array}$ & $\begin{array}{l}\text { 7-Ethox- } \\
\text { yresorufin }\end{array}$ & -8.0 & $\begin{array}{l}\text { ARG517, TYR458, } \\
\text { SER460, TYR459, } \\
\text { VAL477, CYS475, } \\
\text { TRP679 }\end{array}$ \\
\hline
\end{tabular}

With leucine as the ligand, the target protein that it inhibits is 5D6E, Human Methionine Aminopeptidase 2 (MetAP2). When leucine's binding site is compared to the reported inhibitor fumagllin's $\mathrm{s}^{35}$ binding site, leucine binds to 4 out of the 9 amino acid residues that fumagillin binds to. These are ASP262, PHE219, HIS231, and HIS331. Figure 7 and 8 shows the PyMol visualization of both ligands docked on to 5D6E, displaying how they have binded to very similar sites of the protein. Some of the interactions between the residues and leucine include many Salt Bridges, Pi-Alkyl, Pi-Sigma and Positive-Positive interactions. The leucine-5D6E complex has a higher binding energy and docking score in comparison to $3 \mathrm{QFS}$ and it also has many salt bridge interactions at the binding site, which are non-covalent interactions between two ionized sites made up of a hydrogen bond and an electrostatic interaction. Therefore, these interactions make the complex with 5D6E stronger and more stable.

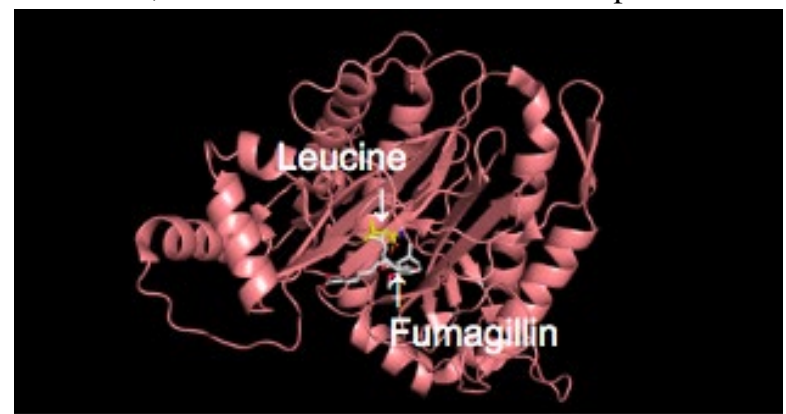

Fig 7

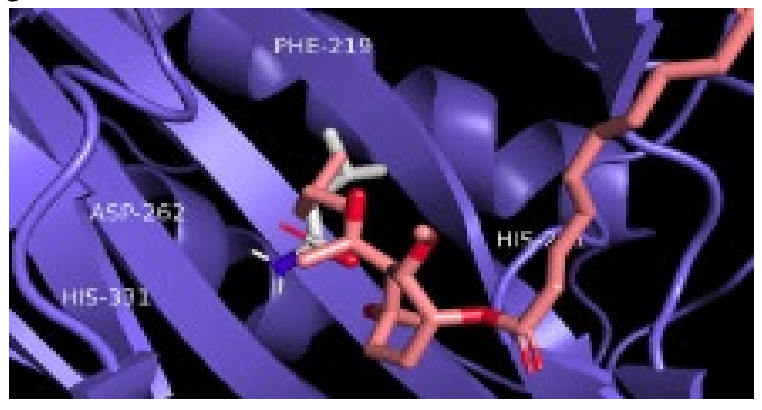

Fig 8 
Figure 7 Leucine and fumagillin bound to Human Methionine Aminopeptidase 2 (MetAP2)

Figure 8 Close-up view of binding complexes with Human Methionine Aminopeptidase 2 (MetAP2) with common binding residues labeled. The light pink ligand is fumagillin and the light grey ligand is leucine.

Table 1.5 Top 30 target proteins scored for L-lysine from ACID

\begin{tabular}{|c|c|c|c|}
\hline PDB Code & Name & $\begin{array}{l}\text { Free Binding } \text { Energy } \\
(\mathrm{kcal} / \mathrm{mol})\end{array}$ & Docking Score $(\mathrm{kcal} / \mathrm{mol})$ \\
\hline $1 \mathrm{~S} 1 \mathrm{D}$ & Apyrase & -56.97 & -6.11 \\
\hline 3T3M & alphaIIbbeta3 Receptor Antagonist & -41.63 & -6.15 \\
\hline $1 \mathrm{CJY}$ & Human Cytosolic Phospholipase A2 & -39.18 & -5.82 \\
\hline $2 \mathrm{KFZ}$ & Klenow Fragment & -30.57 & -5.82 \\
\hline $1 \mathrm{G} 1 \mathrm{~T}$ & E-selectin Lectin/EFG Domans & -29.75 & -5.49 \\
\hline $3 \mathrm{ORH}$ & guanidinoacetate N-methyltransferase & -27.97 & -6.53 \\
\hline 1IMB & Inositol Monophosphatase & -27.87 & -6.15 \\
\hline $1 \mathrm{JZ8}$ & E. Coli Beta-galactosidase & -27.34 & -6.03 \\
\hline $1 \mathrm{KQP}$ & NH3-Dependent NAD+ Snythetase & -25.57 & -6 \\
\hline 4IAR & 5-HT1B-BRIL & -24.87 & -6.33 \\
\hline $2 \mathrm{~F} 25$ & Sialidase Neu2 E111Q Mutant & -24.02 & -6.15 \\
\hline 1QGI & Chitosanase from Bacillus Circulans & -22.85 & -5.88 \\
\hline 4HZE & human Arginase-2 & -22.84 & -6.02 \\
\hline 5HIA & $\begin{array}{l}\text { Human hypoxanthine-guanine phosphori- } \\
\text { bosyltransferase }\end{array}$ & -22.27 & -6.01 \\
\hline 2AEB & human arginase I at 1.29 & -21.88 & -6.16 \\
\hline $3 \mathrm{I} 4 \mathrm{~A}$ & $\begin{array}{l}\text { Dimethylarginine dimethylaminohydro- } \\
\text { lase-1 (DDAH-1) }\end{array}$ & -21.43 & -6.43 \\
\hline 3FE4 & Human Carbonic Anhydrase & -21.38 & -6.15 \\
\hline $3 \mathrm{BIU}$ & human peptidylarginine deiminase 4 & -20.82 & -6.01 \\
\hline 3GR4 & Human Pyruvate Kinase M2 & -19.66 & -6.06 \\
\hline $4 \mathrm{~V} 11$ & Synaptotagmin-1 & -18.67 & -5.96 \\
\hline $4 \mathrm{XCT}$ & $\begin{array}{l}\text { hydroxamate based inhibitor ARP101 } \\
\text { (EN73) }\end{array}$ & -17.6 & -6.62 \\
\hline 3BRT & NEMO/IKK association domain structure & -17.16 & -6.11 \\
\hline $2 \mathrm{ZC} 6$ & $\begin{array}{l}\text { Penicillin-binding protein 1A (PBP 1A) } \\
\text { acyl-enzyme complex (tebipenem) from } \\
\text { Streptococcus pneumoniae }\end{array}$ & -17.03 & -6.13 \\
\hline $4 \mathrm{JNI}$ & uPA & -16.44 & -6.36 \\
\hline 4XIA & D-Xylose Isomerase & -16.35 & -6.46 \\
\hline 2QTL & $\begin{array}{l}\text { FAD-containing FNR-like Module of Hu- } \\
\text { man Methionine Synthase Reductase }\end{array}$ & -16.17 & -6.1 \\
\hline $2 \mathrm{Y} 2 \mathrm{M}$ & Penicillin-Binding Protein (PBP-1B) & -16.17 & -6.03 \\
\hline $1 \mathrm{LI} 4$ & $\begin{array}{l}\text { Human S-adenosylhomocysteine hydro- } \\
\text { lase }\end{array}$ & -15.83 & -6.58 \\
\hline $2 \mathrm{CEV}$ & Arginase from Bacillus Caldevelox & -15.79 & -6.27 \\
\hline 2Y6D & MMP7 Inhibitor & -15.77 & -6.08 \\
\hline
\end{tabular}


Table 2.5 Validation of docking of selected target proteins for L-lysine

\begin{tabular}{|c|c|c|c|c|c|c|}
\hline $\begin{array}{l}\text { PDB } \\
\text { Code }\end{array}$ & Name & Classification & $\begin{array}{l}\text { ACID } \\
\text { Docking } \\
\text { Score } \\
(\mathrm{kcal} / \mathrm{mol})\end{array}$ & $\begin{array}{l}\text { AutoDock } \\
\text { Vina } \\
\text { Docking } \\
\text { Score } \\
(\mathrm{kcal} / \mathrm{mol})\end{array}$ & $\begin{array}{l}\text { AutoDock Vina } \\
\text { Amino Acid Resi- } \\
\text { dues }\end{array}$ & $\begin{array}{l}\text { DS Amino Acid } \\
\text { Residues and Inter- } \\
\text { actions }\end{array}$ \\
\hline $\begin{array}{l}2 \mathrm{AE} \\
\mathrm{B}\end{array}$ & $\begin{array}{l}\text { Human Aarginase I } \\
\text { at } 1.29\end{array}$ & $\begin{array}{l}\text { Hydrolase/ Hydro- } \\
\text { lase Inhibitor }\end{array}$ & -6.16 & -4.9 & $\begin{array}{l}\text { PRO167, PHE147, } \\
\text { PRO157, ILE156, } \\
\text { VAL165, ASP158 }\end{array}$ & $\begin{array}{l}\text { ASP158: } \\
\text { Bridge } \\
\text { VAL165: Conven- } \\
\text { tional Hydrogen } \\
\text { Bond (2), Alkyl } \\
\text { PHE147: Pi-Alkyl } \\
\text { ILE156: Alkyl } \\
\text { PRO157: Conven- } \\
\text { tional Hydrogen } \\
\text { Bond (2) }\end{array}$ \\
\hline $3 \mathrm{BIU}$ & 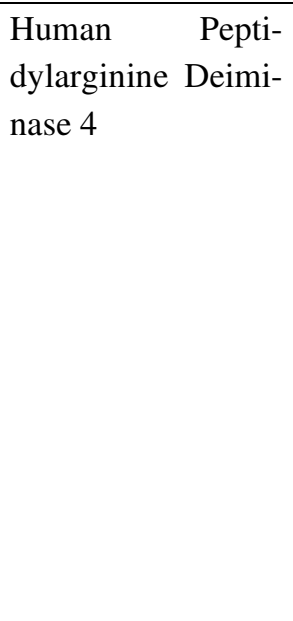 & $\begin{array}{l}\text { Hydrolase/Hydro- } \\
\text { lase Inhibitor }\end{array}$ & -6.01 & -4.3 & $\begin{array}{l}\text { VAL290, SER288, } \\
\text { LEU117* }\end{array}$ & $\begin{array}{lr}\text { ILE121: } & \text { Alkyl } \\
\text { VAL289: Alkyl } \\
\text { VAL290: Conven- } \\
\text { tional Hydrogen } \\
\text { Bond SER288: } \\
\text { Conventional Hy- } \\
\text { drogen Bond (2) } \\
\text { ASP287: Salt } \\
\text { Bridge, Charge- } \\
\text { Charge } \\
\text { LEU117: Conven- } \\
\text { tional Hydrogen } \\
\text { Bond }\end{array}$ \\
\hline
\end{tabular}

* PyMol was used to identify amino acid residues

Table 3.5 L-lysine vs. the reported inhibitors for each target protein

\begin{tabular}{|l|l|l|l|l|l|l|}
\hline $\begin{array}{l}\text { PDB } \\
\text { Code }\end{array}$ & Protein Name & $\begin{array}{l}\text { L-Lysine } \\
\text { ADV } \\
\text { Docking } \\
\text { Score } \\
(\mathrm{kcal} / \mathrm{mol})\end{array}$ & $\begin{array}{l}\text { L-Lysine ADV } \\
\text { Amino Acid Resi- } \\
\text { dues }\end{array}$ & $\begin{array}{l}\text { Reported In- } \\
\text { hibitor Name }\end{array}$ & $\begin{array}{l}\text { Reported } \\
\text { Inhibitor } \\
\text { ADV } \\
\text { Docking } \\
\text { Score } \\
(\mathrm{kcal} / \mathrm{mol})\end{array}$ & $\begin{array}{l}\text { Reported Inhibitor } \\
\text { ADV Amino Acid } \\
\text { Residues }\end{array}$ \\
\hline $\begin{array}{l}2 \mathrm{AE} \\
\mathrm{B}\end{array}$ & $\begin{array}{l}\text { Human Arginase I } \\
\text { at } 1.29\end{array}$ & -4.9 & $\begin{array}{l}\text { PRO167, PHE147, } \\
\text { PRO157, ILE156, } \\
\text { VAL165, ASP158 }\end{array}$ & L-Lysine & -4.9 & $\begin{array}{l}\text { PRO167, PHE147, } \\
\text { PRO157, ILE156, } \\
\text { VAL165, }\end{array}$ \\
\hline
\end{tabular}




\begin{tabular}{|l|l|l|l|l|l|l|}
\hline & & & & & ASP158 \\
\hline 3BIU & $\begin{array}{l}\text { Human Pepti- } \\
\text { dylarginine Deimi- } \\
\text { nase 4 }\end{array}$ & -4.3 & $\begin{array}{l}\text { VAL290, SER288, } \\
\text { LEU117* }\end{array}$ & $\begin{array}{l}\text { GSK484 hy- } \\
\text { drochloride }\end{array}$ & $\begin{array}{l}\text { GLN146, SER288, } \\
\text { VAL290* }\end{array}$ \\
\hline
\end{tabular}

* PyMol was used to identify amino acid residues

With L-lysine as the ligand, it actually inhibits both the target proteins, 2AEB (Human Arginase I) and 3B1U (Human Peptidylarginine Deiminase 4). However, L-lysine's inhibition of Human Arginase I has already been reported ${ }^{36}$, so looking at L-lysine's inhibition of 3B1U will be more novel and significant. When L-lysine's binding site on 3B1U is compared to the reported inhibitor GSK484 hydrochloride's ${ }^{37}$ binding site, L-lysine binds to 2 out of the 3 residues that GSK484 hydrochloride binds to and these residues are SER288 and VAL290. Figure 9 and 10 shows the PyMol visualization of both ligands docked on to 3B1U, displaying how they have binded to the same binding site of the protein. Some of the interactions between the residues and L-lysine include Alkyl, Conventional Hydrogen Bonds, Salt Bridge, and Charge-Charge and these polar bonds and highly attractive nonpolar interactions provide stability and allow 1-lysine to remain bound to $3 \mathrm{~B} 1 \mathrm{U}$ as an inhibitor.

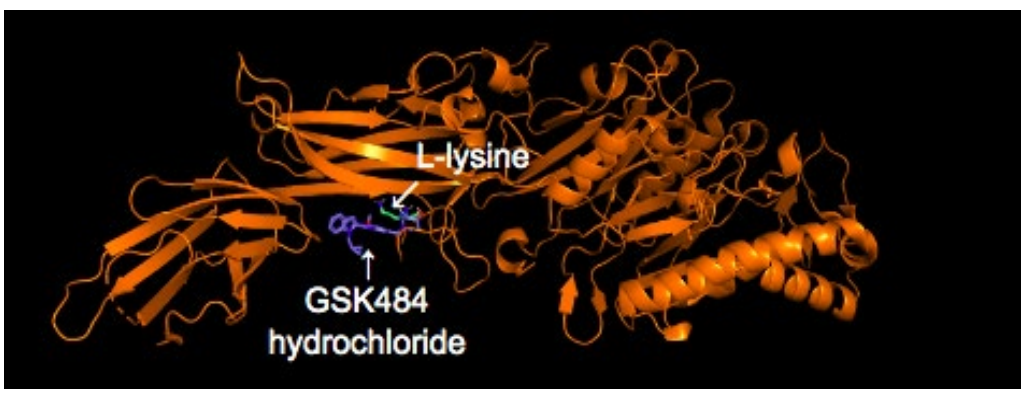

Fig 9

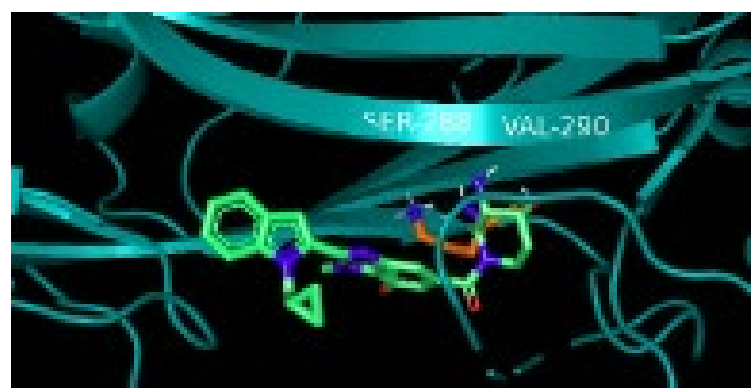

Fig 10

Figure 9 L-lysine and GSK484 hydrochloride bound to Human Peptidylarginine Deiminase 4

Figure 10 Close-up view of binding complexes with Human Peptidylarginine Deiminase 4 with common binding residues labeled. The light green ligand is GSK484 hydrochloride and the orange ligand is L-lysine.

\section{Discussion}

The goal of this project was to find novel protein targets for fenugreek that can help treat diabetes mellitus. Our results show the different target proteins that each phytochemical constituent of fenugreek, exempting diosgenin, is able to inhibit well, but it is more important to look at the significance of these inhibitions and their relevance to diabetes. Trigonelline inhibits low molecular weight Protein tyrosine phosphatase, a member of the PTP family, but is significantly less researched in its potential therapeutic ability in comparison to PTP1B ${ }^{38}$. LMPTP has been proposed to regulate insulin signaling through IR dephosphorylation ${ }^{39}$. Knockdown of LMPTP expression by antisense oligonucleotides improves the glycemic profile and decreases insulin resistance in diet-induced obese (DIO) C57BL/6 (B6) mice $^{40}$ and overexpression of catalytically inactive LMPTP in immortalized mouse fibroblasts increases insulin-induced IR tyrosine phosphorylation ${ }^{41}$, showing that LMPTP regulates insulin signaling through its phosphatase activity. Possible future research could include a deeper study into trigonelline's inhibition of LMPTP, or synthesis of selective LMPTP inhibitors in order to increase insulin secretion in diabetic patients. 4-Hydroxyisoleucine inhibits Nitric Oxide 
Synthase the best, and this protein is a key regulator of endothelial function, which increases skeletal muscle perfusion, and the surface area of capillaries to allow insulin exchange. However, this is the opposite for what is wanted. Several studies have demonstrated that a reduction of nitric oxide synthases diminishes perfusion and glucose uptake in the skeletal muscle in both humans and rodents. Hence, inhibiting nitric oxide synthases is important in improving the condition of patients with type 2 diabetes $^{42}$. Leucine has been shown to inhibit human methionine aminopeptidase 2 , an enzyme that, under normal cellular conditions, methionine aminopeptidase 2 (MetAP2) catalyzes the removal of the N-terminal methionine, the starting amino acid of a polypeptide chain, from novel proteins shortly after translation. In Type II diabetic preclinical studies, MetAP2 inhibitors have shown to produce clinically significant weight loss characteristics and reduced average blood glucose levels ${ }^{43}$. Leucine's high binding affinity to MetAP2 and potential as a MetAP2 inhibitor can help extend the catalog of already synthesized MetAP2 inhibitors. Lastly, in this study, it was found that L-lysine inhibited Human peptidylarginine deiminase 4, a nuclear citrullinating enzyme that is critically involved in the release of decondensed chromatin from neutrophils as neutrophil extracellular traps (NETs). NETs, together with fibrin, are involved in defense against pathogens, but the formation of NETs (NETosis) has negative effects related to many diseases, such as diabetes mellitus ${ }^{44}$. In parallel with increased NETosis, neutrophil PAD4 protein expression is elevated approximately 4-fold in patients with type 1 diabetes mellitus and type 2 diabetes mellitus ${ }^{44}$. Increased NETS levels also create many complications that are often associated with diabetes patients such as impaired wound healing, especially in relation to diabetic foot ulcers ${ }^{45}$, and increased incidences of heart disease and thrombosis ${ }^{46}$. Further research on PAD4 inhibitors like L-lysine would therefore be quite beneficial for diabetic patients.

\section{Conclusion}

The phytoconstituents from fenugreek have long been studied for their anti-diabetic effects in vivo and in vitro, more specifically for their ability to inhibit enzymes such as alpha glucosidase and alpha amylase. In this study, however, we have shown that the specific compounds trigonelline, 4-hydroxyisoleucine, leucine, and L-lysine are capable of inhibiting novel protein targets that can help treat diabetes mellitus in even more ways. It is important to note that we only picked the highest score and best matching protein, but compounds like 4-hydroxyisoleucine binding to other proteins could also result in the compound's biological effects. This study only looks at their ideal mechanism of action since it was only a molecular docking study, so future studies should focus on in-vitro studies that look at these compounds' inhibition of their respective target proteins such as LMPTP. If successful, further research can also be done to create semi-synthetic drugs based on the compounds to target the specific proteins in diabetic patients.

\section{Acknowledgements}

Gayathri Renganathan conceptualized the project, and Haasini Nandyala, Ariel Pham, and Anushka Wagle developed, mended and conducted the majority of the in-silico work. Amrita Guha and Hansika Daggolu assisted with some insilico work. In addition to Haasini Nandyala, Amrita Guha, and Hansika Daggolu, Reya Sankar, Chloe Chan, and Dipti Venkatesh assisted in creating and editing the manuscript. We are also grateful for our advisor's support throughout this project by providing us with ideas to improve our work. We would like to thank the Aspiring Scholars Directed Research Program (ASDRP) in Fremont, CA for supporting us with the facilities and funding to conduct this research. Furthermore, we thankfully acknowledge Edward Njoo for providing us with suggestions on our manuscript.

\section{References}

Rampogu, S., Parameswaran, S., Lemuel, M. R., \& Lee, K. W. (2018). Exploring the Therapeutic Ability of Fenugreek against Type 2 Diabetes and Breast Cancer Employing Molecular Docking and Molecular Dynamics 
Simulations. Evidence-based complementary and alternative medicine : eCAM, 2018, 1943203. https://doi.org/10.1155/2018/1943203

Gaddam, A., Galla, C., Thummisetti, S., Marikanty, R., Palanisamy, U., \& Rao, P. (2015, October 2). Role of Fenugreek in the prevention of type 2 diabetes mellitus IN prediabetes. Retrieved April 28, 2021

Al-Timimi, L. (2019, December 1). Antibacterial and anticancer activities of fenugreek seed extract. Retrieved April 28,2021

Saxena, B., Saxena, U.. (2009, January). Anti-hyperlipidemic activity of fenugreek (Trigonella foenum-graecum) seeds extract in triton and high fat diet induced hyperlipidemic model: A potent anti-antherosclerotic agent.

Pharmacologyonline. 2. 616-624. Retrieved May 8, 2021

Habib-Martin, Z., Hammad, H., Afifi, F., Zihlif, M., Al-Ameer, H., Saleh, M., . . Nassar, Z. (2017, August 03). In vitro and in vivo evaluation of the antiangiogenic activities of trigonella foenum-graecum extracts. Retrieved April 28,2021

Taj Eldin, I., Abdalmutalab, M., \& Bikir, H. (2013). An in VITRO anticoagulant effect Of fenugreek (Trigonella foenum-graecum) in blood samples of NORMAL Sudanese individuals. Retrieved April 28, 2021

Jesus, M., Martins, A., Gallardo, E., \& Silvestre, S. (2016). Diosgenin: Recent highlights on pharmacology and analytical methodology. Retrieved April 28, 2021

Ahmed M.A. Abd-El M., Husam O. (2011). Elicitation of Trigonelline and 4-Hydroxyisoleucine with Hypoglycemic Activity in Cell Suspension Cultures of Trigonella foenum graecum L. The Open Conference Proceedings Journal. Retrieved May 8, 2021

Garg, R. (2016, February 19). Fenugreek: Multiple health benefits. Retrieved April 28, 2021

Mansour, E., \& El-Adawy, T. (2002, May 25). Nutritional potential and functional properties of heat-treated and germinated fenugreek seeds. Retrieved April 28, 2021

Worldwide toll of diabetes. (2019). International Diabetes Federation.

https://www.diabetesatlas.org/en/sections/worldwide-toll-of-

diabetes.html\#:\%7E:text=Today\%2C\%20we\%20calculate\%20that\%209.3,in\%202025\%20was\%20438\%20million.

Baquer, N.Z., Kumar, P., Taha, A. et al. Metabolic and molecular action of Trigonella foenum-graecum (fenugreek) and trace metals in experimental diabetic tissues. J Biosci 36, 383-396 (2011).

JI;, P. M. V. M. (n.d.). The metabolic syndrome: definition, global impact, and pathophysiology. Nutrition in clinical practice : official publication of the American Society for Parenteral and Enteral Nutrition

The pathogenesis and pathophysiology of type 1 and type 2 diabetes mellitus. Ozougwu, J. C., Obimba, K. C.,

Belonwu, C. D., and Unakalamba, C. B. JPAP 2017, DOI: 10.5897/JPAP2013.0001

Diabetes 2030: insights from yesterday, today, and future trends. Rowley WR, Bezold C, Arikan Y, Byrne E, Krohe S. Popul Health Manag. 2017;20:6-12

Habtemariam, S. "Chapter 17 - The chemical and pharmacological basis of fenugreek (Trigonella foenum-graecum L.) as potential therapy for type 2 diabetes and associated diseases." Medicinal Foods as Potential Therapies for Type-2 Diabetes and Associated Diseases- The Chemical and Pharmacological Basis of their Action, 2019, p. 579637

Kumar, S., Narwal, S., Kumar, V., \& Prakash, O. (2011, January). A-Glucosidase inhibitors from plants: A natural approach to treat diabetes. Retrieved April 28, 2021

Agarwal, P., Gupta, R. (September 2016). Alpha-amylase inhibition can treat diabetes mellitus. Journal of Medical Physics. 5(4). Retrieved May 8, 2021

Ghosh, S., More, P., Derle, A., Patil, A., Markad, P., Asok, A., . . Chopade, B. (n.d.). Diosgenin from Dioscorea Bulbifera: NOVEL hit for treatment of Type II diabetes Mellitus with inhibitory activity AGAINST $\alpha$-Amylase And $\alpha$-glucosidase. Retrieved April 28, 2021

Jemal, K. (2019, January 01). Molecular docking studies of PHYTOCHEMICALS of allophylus serratus Against cyclooxygenase-2 enzyme. Retrieved April 28, 2021 
National Center for Biotechnology Information (2021). PubChem Compound Summary for CID 5570, Trigonelline. Retrieved May 7, 2021

National Center for Biotechnology Information (2021). PubChem Compound Summary for CID 99474, Diosgenin. Retrieved May 7, 2021

National Center for Biotechnology Information (2021). PubChem Compound Summary for CID 5962, Lysine. Retrieved May 7, 2021

National Center for Biotechnology Information (2021). PubChem Compound Summary for CID 6106, Leucine. Retrieved May 7, 2021

National Center for Biotechnology Information (2021). PubChem Compound Summary for CID 2773624, 4Hydroxyisoleucine. Retrieved May 7, 2021

H.M. Berman, J. Westbrook, Z. Feng, G. Gilliland, T.N. Bhat, H. Weissig, I.N. Shindyalov, P.E. Bourne. (2000) The Protein Data Bank Nucleic Acids Research, 28: 235-242.

Wang, F., Wu, F., Li, C., Jia, C., Su, S., Hao, G., \& Yang, G. (2019, November 27). Acid: A free tool for drug repurposing using consensus inverse docking strategy. Retrieved April 28, 2021

O. Trott, A. J. Olson, AutoDock Vina: improving the speed and accuracy of docking with a new scoring function, efficient optimization, and multithreading, Journal of Computational Chemistry 31 (2010) 455-461 DOI $10.1002 /$ jcc. 21334

Ref. Dassault Systèmes BIOVIA, Discovery Studio Modeling Environment, Release 2017, San Diego: Dassault Systèmes, 2016.

The PyMOL Molecular Graphics System, Version 1.2r3pre, Schrödinger, LLC.

Roskoski R., Jr (2019). Targeting ERK1/2 protein-serine/threonine kinases in human cancers.Pharmacological research, 142, 151-168. https://doi.org/10.1016/j.phrs.2019.01.039

Wójcikowski, J., Danek, P. J., Basińska-Ziobroń, A., Pukło, R., \& Daniel, W. A. (2020, March 26). In vitro inhibition of human cytochrome P450 enzymes by the novel atypical antipsychotic drug asenapine: a prediction of possible drug-drug interactions. Pharmacological Reports.

Stanford, S. M., Aleshin, A. E., Zhang, V., Ardecky, R. J., Hedrick, M. P., Zou, J., ... Bottini, N. (2017, March 27). Diabetes reversal by inhibition of the low-molecular-weight tyrosine phosphatase. Nature News.

Víteček, J., Lojek, A., Valacchi, G., \& Kubala, L. (2012, September 4). Arginine-Based Inhibitors of Nitric Oxide Synthase: Therapeutic Potential and Challenges. Mediators of Inflammation.

Sin N;Meng L;Wang MQ;Wen JJ;Bornmann WG;Crews CM; (n.d.). The anti-angiogenic agent fumagillin covalently binds and inhibits the methionine aminopeptidase, MetAP-2. Proceedings of the National Academy of Sciences of the United States of America.

Di Costanzo, L., Ilies, M., Thorn, K. J., \& Christianson, D. W. (2010, April 15). Inhibition of human arginase I by substrate and product analogues. Archives of biochemistry and biophysics.

Du, M., Yang, L., Gu, J., Wu, J., Ma, Y., \& Wang, T. (2020, December 30). Inhibition of Peptidyl Arginine Deiminase-4 Prevents Renal Ischemia-Reperfusion-Induced Remote Lung Injury. Mediators of Inflammation. Stanford, S., Aleshin, A., Zhang, V., Ardecky, R., Hedrick, M., Zou, J., . . Bottini, N. (2017, June). Diabetes reversal by inhibition of the low-molecular-weight tyrosine phosphatase. Retrieved April 28, 2021

LMW-PTP is a negative regulator of insulin-mediated mitotic and metabolic signalling. Chiarugi P, Cirri P, Marra F, Raugei G, Camici G, Manao G, Ramponi G Biochem Biophys Res Commun. 1997 Sep 18; 238(2):676-82. Reduction of low molecular weight protein-tyrosine phosphatase expression improves hyperglycemia and insulin sensitivity in obese mice. Pandey SK, Yu XX, Watts LM, Michael MD, Sloop KW, Rivard AR, Leedom TA, Manchem VP, Samadzadeh L, McKay RA, Monia BP, Bhanot S J Biol Chem. 2007 May 11; 282(19):14291-9. LMW-PTP is a negative regulator of insulin-mediated mitotic and metabolic signalling. Chiarugi P, Cirri P, Marra F, Raugei G, Camici G, Manao G, Ramponi G Biochem Biophys Res Commun. 1997 Sep 18; 238(2):676-82. Williams, I., McClatchey, P., Bracy, D., Valenzuela, F., \& Wasserman, D. (2018, October 01). Acute nitric oxide synthase inhibition accelerates transendothelial insulin efflux in vivo. Retrieved April 28, 2021 
Proietto, J., Malloy, J., Zhuang, D., Arya, M., Cohen, N., Looze, F., . . Kim, D. (2018, July 11). Efficacy and safety of methionine aminopeptidase 2 inhibition in type 2 DIABETES: A randomised, placebo-controlled clinical trial. Retrieved April 28, 2021

Wong, S. L., \& Wagner, D. D. (2018). Peptidylarginine deiminase 4: a nuclear button triggering neutrophil extracellular traps in inflammatory diseases and aging. FASEB journal : official publication of the Federation of American Societies for Experimental Biology, 32(12), fj201800691R. Advance online publication.

https://doi.org/10.1096/fj.201800691R

Wong, S. L., Demers, M., Martinod, K., Gallant, M., Wang, Y., Goldfine, A. B., Kahn, C. R., and Wagner, D. D. (2015) Diabetes primes neutrophils to undergo NETosis, which impairs wound healing. Nat. Med. 21, 815-819 Laakso, M., and Kuusisto, J. (2014) Insulin resistance and hyperglycaemia in cardiovascular disease development. Nat. Rev. Endocrinol. 10, 293-302 Morel, O., Jesel, L., Abbas, M., and Morel, N. (2013) Prothrombotic changes in diabetes mellitus. Semin. Thromb. Hemost. 39, 477-488 